\title{
Milho com diferentes graus de moagem em combinação com polpa cítrica peletizada ou casca de soja para vacas leiteiras no terço médio da lactação ${ }^{1}$
}

\author{
Flávio Augusto Portela Santos ${ }^{2}$, Carolina de Almeida Carmo ${ }^{3}$, Carla Maris Machado Bittar², \\ Alexandre Vaz Pires ${ }^{2}$, Alexandre Mendonça Pedroso ${ }^{3}$, Eduardo Menegueli Pereira ${ }^{4}$
}

\footnotetext{
${ }^{1}$ Financiado pela FAPESP.

2 Depto. de Zootecnia, USP/ESALQ, Caixa Postal 9, CEP: 13418-900, Piracicaba, SP

${ }^{3}$ Doutorando em Ciência Animal e Pastagens, USP/ESALQ, Caixa Postal 9, CEP: 13418-900, Piracicaba, SP

${ }^{4}$ Mestrando em Ciência Animal e Pastagens, USP/ESALQ, Caixa Postal 9, CEP: 13418-900, Piracicaba, SP.
}

RESUMO - Avaliou-se o efeito do grau de moagem do milho (moído fino ou moído grosso) em dietas com polpa cítrica peletizada ou casca de soja sobre o desempenho lactacional de vacas leiteiras. O período experimental teve duração de 56 dias, divididos em quatro períodos de 14 dias. Trinta e duas vacas holandesas (160 dias em lactação) foram alocadas em oito quadrados latinos, compostos de quatro períodos e quatro dietas: MFPC - milho moído fino + polpa cítrica; MGPC - milho moído grosso + polpa cítrica; MFCS - milho moído fino + casca de soja; e MGCS - milho moído grosso + casca de soja. A ingestão de MS a produção de leite, os teores de gordura, proteína e lactose do leite e as concentrações de glicose e nitrogênio uréico plasmáticos não foram afetados pelas dietas. Houve efeito significativo da interação grau de moagem $\times$ fonte de energia sobre a produção de leite corrigida para gordura e a produção de gordura e de sólidos totais do leite. O grau de moagem do milho e o tipo de subproduto (polpa cítrica ou casaca de soja) não afetaram o desempenho de vacas leiteiras no terço médio da lactação com produção média de 24 kg de leite/dia.

Palavras-chave: composição do leite, fonte de energia, processamento de grãos, subprodutos

\section{Effects of corn particle size and byproduct source on performance of mid- lactating dairy cows}

\begin{abstract}
The objective of this trial was to investigate the effects of feeding corn with different particle size (coarse vs. fine grinding) plus dried citrus pulp or soyhulls on performance of lactating dairy cows. Thirty-two mid lactating Holstein cows averaging 160 days in milk were randomly assigned to eight replicated 4 x 4 Latin squares with a 2 x 2 factorial arrangement of treatments. Animals were fed total mixed rations containing corn silage as the sole forage source. Each experimental period lasted 14 days with 10 days for diet adaptation and four days for data and sample collection. The treatments were: MFPC - finely ground corn + citrus pulp; MGPC - coarsely ground corn + citrus pulp; MGPC - finely ground corn + soyhulls; and MGCS - coarsely ground corn + soyhulls. There were no effect of diet on dry matter intake, milk yield, milk contents of fat, protein and lactose, and plasma concentrations of urea nitrogen and glucose. Significant interactions between corn particle size and byproduct source (dried citrus pulp or soyhulls) were observed for fat corrected milk, and yields of milk fat and milk total solids. It can be concluded that cow performance was not significantly affected by corn processing and byproduct source in the present study.
\end{abstract}

Key Words: byproducts, energy source, grain processing, milk composition

\section{Introdução}

Os grãos de cereais são algumas das principais fontes de energia em dietas para vacas leiteiras de alta produção. Maximizar a digestibilidade desses cereais é uma das formas mais eficientes de aumentar o consumo de energia pelo animal. Uma alternativa para aumentar a digestibilidade dos grãos de cereais é otimizar seu processamento (Theurer et al., 1999).

Em revisão, Theurer et al. (1999) demonstraram que o processamento de milho e sorgo na forma floculada, em comparação à moagem ou laminação, favorece o desempenho produtivo de vacas leiteiras. A moagem fina tem apresentado vantagens em relação à moagem grosseira em alguns estudos (Nussio et al., 2002; Dhiman et al., 2002). Entretanto, são escassas as pesquisas sobre o processamento de grãos para vacas alimentadas com silagem de milho como volumoso exclusivo.

A análise dos dados disponíveis na literatura não permite afirmar se existe um teor ideal de amido total e de amido degradável no rúmen em dietas para vacas leiteiras 
com silagem de milho como principal volumoso. Também são escassos na literatura dados sobre os efeitos da redução no teor de amido na dieta por meio da substituição de grãos de cereais por subprodutos não amiláceos, como polpa cítrica e casca de soja, em dietas contendo silagem de milho.

A polpa cítrica tem sido utilizada em crescente escala no Brasil para vacas leiteiras, em substituição parcial ou total ao milho. A polpa é rica em fibra de alta digestibilidade, em pectina e açúcares (Wainman \& Dewey, 1998). Em alguns estudos (Santos et al., 2001; Nussio et al., 2002; Scoton, 2003; Martinez, 2004; Moreira et al., 2004) com vacas com produção abaixo de 25 kg de leite/dia, a produção não foi prejudicada pela substituição de $50 \%$ do milho por polpa cítrica na dieta.

A casca de soja é composta principalmente de fibra, que tem pouco valor na alimentação humana e no uso industrial. No entanto, suas características fisico-químicas, a facilidade de aquisição em algumas regiões e seu preço competitivo tornam esse resíduo agroindustrial um alimento interessante para o gado leiteiro.

Além disso, como alternativa econômica, a substituição de grãos de cereais por casca de soja em dietas para vacas leiteiras pode contribuir para um ambiente ruminal mais favorável para a digestão de fibra e com menor risco de acidose. Alternativamente, a casca de soja pode ser usada como fonte de fibra em substituição parcial ao volumoso.

Ipharraguerre \& Clark (2003) fizeram análises de regressão múltipla utilizando dados de estudos selecionados para avaliar a relação entre o desempenho de vacas leiteiras e a substituição do milho pela casca de soja. Em 13 de 15 estudos, não houve diferença na ingestão de matéria seca entre animais alimentados com dietas controle e aqueles que receberam casca de soja. A correlação entre a produção de leite e a porcentagem de casca de soja na ração, em dez estudos, foi baixa e não-significativa. O teor de gordura do leite não se correlacionou com o teor de casca de soja na ração ou com o teor de FDN da casca de soja, em dez dos 15 estudos revisados por Ipharraguerre \& Clark (2003).

Este trabalho foi realizado com o objetivo de avaliar o desempenho de vacas em lactação alimentadas com dietas compostas de milho com diferentes graus de moagem (fina ou grossa) em combinação com polpa cítrica peletizada ou casca de soja.

\section{Material e Métodos}

O experimento foi conduzido nas instalações do Departamento de Zootecnia da Escola Superior de Agricultura “Luiz de Queiroz”, Universidade de São Paulo, entre os meses de dezembro de 2002 a fevereiro de 2003.

Foram utilizadas 32 vacas holandesas aos 160 dias de lactação ( $\pm 160 \mathrm{~d}$ ) e produção de leite de $24 \mathrm{~kg} / \mathrm{dia}$, em média. Os animais foram alocados em sistema de confinamento do tipo free-stall com quatro lotes, cada um com 12 baias.

Avaliou-se a combinação de diferentes graus de moagem do milho - moído fino (tamanho médio de partícula $=0,98 \mathrm{~mm}$ ) e moído grosso (tamanho médio de partícula $=2,05 \mathrm{~mm}$ ) - com duas fontes de carboidratos nãoestruturais não-amiláceos (polpa cítrica peletizada e casca de soja) em dietas para vacas leiteiras. Para determinação do tamanho médio de partículas do milho moído, utilizou-se a técnica de peneiras, descrita por Yu et al. (1998) (Tabela 1). As dietas foram formuladas conforme exigências descritas pelo NRC (2001) para suprirem quantidades adequadas de proteína degradável no rúmen e proteína metabolizável. Os ingredientes utilizados foram: silagem de milho, milho moído, farelo de algodão, polpa cítrica peletizada, casca de

Tabela 1 - Tamanho médio de partículas do milho processado Table 1 - Mean particle size of processed corn

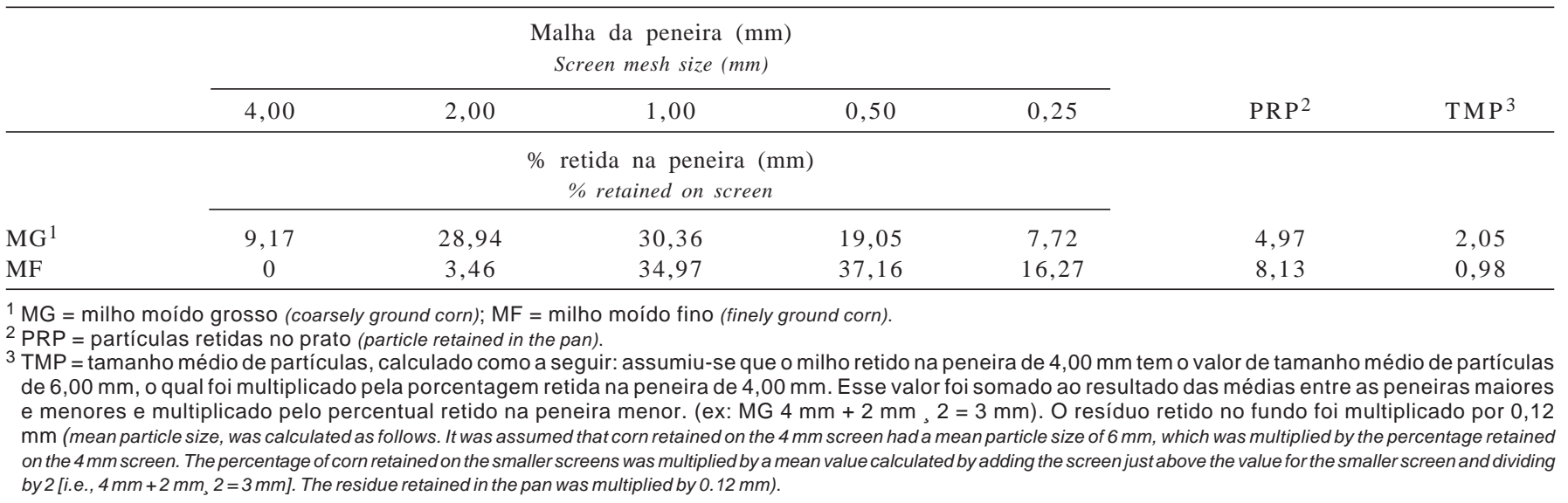


soja, uréia, suplemento mineral e vitamínico e bicarbonato de sódio (Tabela 2).

O período experimental teve duração de 56 dias, divididos em quatro subperíodos de 14 dias. Os dez primeiros dias foram para adaptação dos animais às dietas e os outros quatro, para coleta de dados. Dez dias de adaptação foram adotados com base em outros trabalhos nos quais também foram avaliados os efeitos do processamento do milho (grau de moagem ou laminação) sobre a produção e composição do leite (Joy et al., 1997; Crocker et al., 1998; Callison et al., 2001).

A condição corporal foi avaliada e os animais foram pesados, no início e no final do período experimental, utilizando-se escala de 1 a 5 , de acordo com Wildman et al. (1982).

Os animais foram ordenhados duas vezes ao dia (6h e 18h) e as produções de leite individuais foram registradas nos quatro dias de coleta de dados, por meio de medidores do tipo "Mark V". Amostras de leite de cada vaca também foram coletadas nesses dias, nas ordenhas da manhã e da tarde, para formação de amostras compostas por dia. As amostras compostas foram analisadas quanto aos teores de gordura, proteína, lactose e sólidos totais, pelo processo de infravermelho pelo analisador Bentley 2000 (Bentley Instruments), e nitrogênio uréico, pelo analisador ChemSpec

Tabela 2 - Composição das dietas experimentais Table 2 - Ingredient composition of the experimental diets

\begin{tabular}{lcccc}
\hline & MFPC $^{1}$ & MFCS & MGPC & MGCS \\
\cline { 2 - 5 } & \multicolumn{4}{c}{$\begin{array}{c}\text { \% da MS } \\
\text { \%of DM }\end{array}$} \\
\cline { 2 - 5 } & 45,63 & 45,43 & 45,63 & 45,43 \\
\hline $\begin{array}{l}\text { Silagem de milho } \\
\text { Corn silage }\end{array}$ & 13,23 & 13,27 & 0,00 & 0,00 \\
$\begin{array}{l}\text { Milho moído fino } \\
\text { Finely ground corn }\end{array}$ & 0,00 & 0,00 & 13,23 & 13,27 \\
$\begin{array}{l}\text { Milho moído grosso } \\
\text { Coarsely ground corn }\end{array}$ & 13,00 & 0,00 & 13,00 & 0,00 \\
$\begin{array}{l}\text { Polpa cítrica } \\
\text { Citrus pulp }\end{array}$ & 0,00 & 13,03 & 0,00 & 13,03 \\
$\begin{array}{l}\text { Casca de soja } \\
\text { Soyhulls }\end{array}$ & 0,92 & 0,48 & 0,92 & 0,48 \\
$\begin{array}{l}\text { Uréia } \\
\text { Urea }\end{array}$ & 23,80 & 24,37 & 23,80 & 24,37 \\
$\begin{array}{l}\text { Farelo de algodão } \\
\text { Cottonseed meal }\end{array}$ & 2,70 & 2,69 & 2,70 & 2,69 \\
$\begin{array}{l}\text { Supl. min. vit. } \\
\text { Vitamins and minerals }\end{array}$ & 0,72 & 0,72 & 0,72 & 0,72 \\
$\begin{array}{l}\text { Bicarbonato de Na } \\
\text { Sodium bicarbonate }\end{array}$ & & &
\end{tabular}

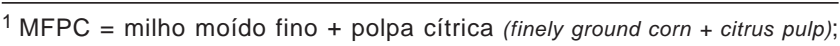
MFCS = milho moído fino + casca de soja (finely ground corn + soyhulls); MGPC = milho moído grosso + polpa cítrica (coarsely ground corn + citrus pulp); MGCS = milho moído grosso + casca de soja (coarsely ground corn + soyhulls).

2 Suplemento mineral e vitamínico, contendo por kg (vitamin and mineral supplement, amount per $\mathrm{kg}$ ): P - 55,0 g; Ca - 220,0 g; Cl - 105,5 g; Na - 70,0 g; Mg - 35,0 g; S - 22,0 g; Mn - 1.500,0 mg; Fe - 500,0 mg; Zn - 1.550,0 mg; Cu - 450,0 mg; Co - 50,0 mg; I - 40,0 mg; Se - 20,0 mg; F - 550,0 mg; vit. A - 90.000 UI; vit. D - 75.000 UI; vit. E - 1.000 UI.
150 (Bentley Instruments), no Laboratório da Clínica do Leite do Departamento de Zootecnia da Escola Superior de Agricultura “Luiz de Queiroz”, Universidade de São Paulo.

As dietas foram distribuídas às $6 \mathrm{~h}$ e às $18 \mathrm{~h}$ e as sobras de alimento foram mensuradas e descartadas diariamente antes do fornecimento no período da tarde. O consumo de alimento foi medido em grupo, por tratamento, diariamente, durante os quatro dias de coleta de dados.

Amostras das dietas e das sobras foram retiradas nos quatro dias de coleta de dados. A silagem foi amostrada semanalmente e os demais alimentos, no início de cada período de coleta de dados. As amostras de silagem e dietas foram armazenadas a $-18^{\circ} \mathrm{C}$. Subamostras da silagem foram secas imediatamente após a amostragem, a $105^{\circ} \mathrm{C}$ por 24 horas, para determinação da MS, a fim de ajustar a quantidade de silagem a ser fornecida.

Após o período experimental, as amostras de alimentos e de dietas foram secas a $55^{\circ} \mathrm{C}$ (em estufa com circulação forçada por 72 horas) para determinação da MS (3 horas em estufa a $105^{\circ} \mathrm{C}$ ), $\mathrm{MO}\left(3\right.$ horas em mufla a $600^{\circ} \mathrm{C}$ ), FDN e FDA, utilizando-se o digestor do tipo Ankom, de acordo com Van Soest et al. (1991), utilizando-se $\alpha$-amilase termoestável, PB, por meio de condução térmica no equipamento Leco FP 528 (Leco Corporation, St. Joseph MI), e amido, conforme método descrito por Poore et al. (1993). Foi determinada apenas a MS das amostras de sobras para cálculo da ingestão de MS pelos animais. As análises foram realizadas no Laboratório de Bromatologia do Departamento de Zootecnia da Escola Superior de Agricultura “Luiz de Queiroz”, Universidade de São Paulo.

As amostras de sangue foram coletadas em tubos com fluoreto de sódio como antiglicolítico e oxalato de potássio como anticoagulante no último dia de coleta de dados, 4 horas após alimentação. As amostras foram centrifugadas em $3.000 \mathrm{x} g$ por 20 minutos, armazenadas em tubos de $2 \mathrm{~mL}$ tipo eppendorf a $-10^{\circ} \mathrm{C}$ e posteriormente analisadas quanto à concentração de glicose, no auto-analisador bioquímico YSI 2700S (Yellow Springs Instrument Co. Inc., Ohio, USA), e de uréia, pelo kit analisa (Analisa Indústria e Comércio Ltda.), método colorimétrico. As análises de glicose foram realizadas no Laboratório de Bromatologia do Departamento de Zootecnia da Escola Superior de Agricultura “Luiz de Queiroz”, Universidade de São Paulo, e as de uréia, no Biomed Laboratórios de Análises Clínicas. O valor de uréia foi convertido para nitrogênio uréico, considerando 46,6\% de nitrogênio na uréia.

Os experimento foi montado em esquema fatorial $2 \times 2$ (dois tipos de subprodutos e dois graus de moagem do milho), em delineamento quadrado latino $4 \times 4$ repetido. Foram utilizados 32 animais distribuídos em oito quadrados 
latinos. Os dados de consumo foram analisados como um quadrado latino simples, visto que o consumo de alimento foi medido em grupo e não individualmente. Assim, cada grupo de animais de cada tratamento foi considerado a unidade experimental.

Os dados foram analisados pelo PROC GLM (General Linear Models) do programa estatístico SAS (1999), versão 8 para Windows. Aplicou-se o teste de comparação de médias dos quadrados mínimos para estudo dos efeitos de grau de moagem ou de fonte de subproduto, além de suas interações (tratamentos). Considerou-se o nível de significância de $5 \%$ e até $10 \%$ como tendência de significância para a probabilidade do teste $\mathrm{F}$ na análise de variância e no teste de comparação de médias.

\section{Resultados e Discussão}

Como descrito na Tabela 3, o teor de MS da silagem de milho foi menor que o preconizado, de 32 a 35\% (NRC, 2001). Os valores de FDN e FDA do milho e de FDA da polpa cítrica foram menores que aqueles apresentados nas tabelas do NRC (2001). A composição das dietas foi estimada a partir dos resultados da composição dos ingredientes. Nesses cálculos, o teor de amido da polpa cítrica foi considerado $0,5 \%$ por estar mais próximo dos valores encontrados na literatura (Wainman \& Dewey, 1988).

Os pesos vivos e os escores de condição corporal médios de todos os animais, no início e no final do experimento, foram $568 \mathrm{~kg} ; 570 \mathrm{~kg}$; 2,75 e 2,75, respectivamente.

A ingestão de MS não foi afetada $(\mathrm{P}>0,05)$ pelo grau de moagem do milho (Tabela 4). San Emeterio et al. (2000) e Dhiman et al. (2002) também não observaram diferenças na ingestão de MS quando compararam milho moído fino e milho moído grosso.

Em alguns trabalhos, tem-se observado o efeito do processamento de grãos na ingestão de MS. Nussio et al. (2002) compararam diferentes formas de processamento de milho para vacas em final de lactação alimentadas com dietas com silagem de milho como volumoso e observaram resultados diferentes dos obtidos neste estudo, com tendência de aumento da ingestão de MS nas vacas que receberam milho moído fino em comparação ao moído grosso ou floculado. Por outro lado, Yu et al. (1998) notaram que vacas alimentadas com dietas contendo milho moído fino apresentaram menor ingestão de MS se comparadas àquelas alimentadas com dietas contendo milho moído grosso quando fornecido feno de alfafa como volumoso.

É possível que, dependendo do grau de moagem do milho, haja influência da umidade da dieta sobre a ingestão de MS. Em dietas com alto teor de MS, como as utilizadas por Yu et al. (1998), a moagem fina pode aumentar a quantidade de pó e limitar a ingestão pelos animais. No entanto, em dietas totalmente misturadas e com maior teor de umidade, como ocorre quando se utiliza volumoso conservado na forma de silagem, como a silagem de milho, é provável que esse problema seja eliminado. A maior ingestão de MS observada por Nussio et al. (2002) para milho moído fino pode ser conseqüência da maior taxa de passagem pelo rúmen, em comparação ao milho moído grosso. De modo geral, os dados de literatura comprovam que não há consistência quanto ao efeito do grau de moagem na ingestão de MS.

O tipo de subproduto utilizado, polpa cítrica ou casca de soja, não afetou $(\mathrm{P}>0,05)$ a ingestão de MS. Dados na literatura comparando polpa cítrica e casca de soja para

Tabela 3 - Composição dos ingredientes e das dietas

Table 3 - Chemical composition of feeds and experimental diets

\begin{tabular}{lcrrrr} 
& MS (\%) & & \multicolumn{3}{c}{ \% da MS } \\
DM of DM
\end{tabular}

${ }^{1}$ MFPC = milho moído fino + polpa cítrica peletizada (finely ground corn + citrus pulp); MFCS = milho moído fino + casca de soja (finely ground corn + soyhulls) MGPC = milho moído grosso + polpa cítrica peletizada (coarsely ground corn + citrus pulp); MGCS = milho moído grosso + casca de soja (coarsely ground corn + soyhulls)

* Considerado valor de tabela de 0,5\% (Table value: $0.5 \%)$ 
Tabela 4 - Valores médios de ingestão de MS, eficiência alimentar, produção e composição do leite, glicose e nitrogênio uréico plasmático Table 4 - Average values of DM intake, feed efficiency, milk yield and composition, and plasma concentrations of glucose and urea nitrogen

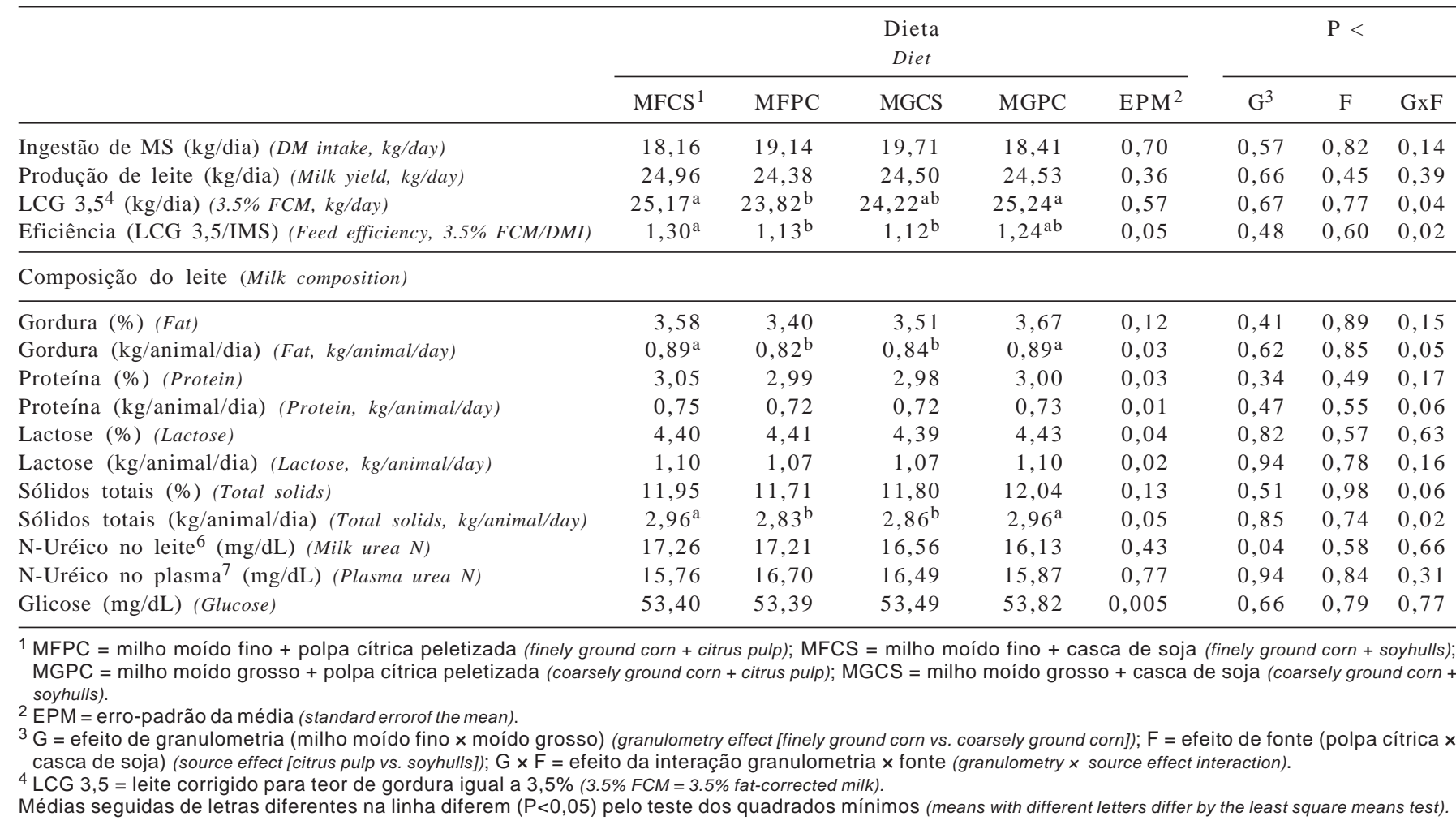

vacas leiteiras são escassos e, considerando a composição bromatológica e a alta palatabilidade destes ingredientes, não seriam esperadas grandes diferenças entre esses subprodutos quanto à ingestão de MS.

A produção de leite não foi afetada pelo grau de moagem do milho nem pelo tipo de subproduto ( $\mathrm{P}>0,05)$, semelhantemente ao observado por San Emeterio et al. (2000) e Callison et al. (2001).

Soriano et al. (2000) e Reis et al. (2001) também não observaram diferença na produção de leite quando forneceram milho com diferentes granulometrias para vacas em lactação mantidas em pastagem. Soriano et al. (2000) forneceram 6 ou $4 \mathrm{~kg}$ MS de milho com diferentes granulometrias para vacas mantidas em pastagens, enquanto Reis et al. (2001) suplementaram a dieta de vacas com aproximadamente 8 kg MS de milho moído fino ou milho de alta umidade moído fino ou moído grosso. Nesses trabalhos, as quantidades de milho fornecidas foram altas e podem ter resultado em ingestão excessiva de amido.

A ausência de efeito positivo do processamento mais intenso, ou seja, a moagem fina em comparação à moagem grossa, difere dos dados de Wilkerson et al. (1997), Yu et al. (1998), Theurer et al. (1999) e Dhiman et al. (2002).

Os resultados deste estudo também diferem do encontrado por Yu et al. (1998), que observaram produção de leite maior em vacas alimentadas com milho floculado (360 g/L), produção intermediária com milho moído fino e menor produção com milho moído grosso, laminado ou floculado excessivamente (309 g/L). A maior produção de leite pelas vacas alimentadas com milho floculado com densidade média e com milho moído fino está associada à maior disponibilidade de energia dos grãos, principalmente em razão da maior degradação ruminal do amido. Maior quantidade de amido degradável no rúmen aumenta o desempenho lactacional, provavelmente em virtude da maior produção de ácidos graxos voláteis e da maior produção microbiana. É provável que a menor produção em vacas alimentadas com milho floculado excessivamente (309 g/L) tenha sido causada por excessiva degradação ruminal de amido, que pode ter resultado em $\mathrm{pH}$ ruminal muito baixo. Por apresentarem menor ingestão de MS, vacas alimentadas com a dieta contendo milho moído fino apresentaram maior eficiência de conversão de alimento em leite se comparadas às alimentadas com milho moído grosso ou floculado.

Dhiman et al. (2002) também observaram maior produção de leite, porém com teor de gordura mais baixo, em vacas alimentadas com dieta formulada com milho moído fino ou milho floculado em comparação às que receberam milho moído grosso. 
Alguns autores compararam a moagem a outros métodos de processamento e obtiveram melhores resultados com a moagem. Segundo Wilkerson et al. (1997), a produção de leite em vacas alimentadas com milho moído foi $2,2 \mathrm{~kg} / \mathrm{dia}$ maior que a obtida em vacas que receberam milho laminado. De acordo com esses autores, a redução no tamanho de partícula e o subseqüente aumento na área superficial no milho moído, em comparação ao milho laminado, aumentou a digestibilidade dos nutrientes no trato digestório total.

Knowlton et al. (1998) também observaram que a produção de leite foi maior quando foi fornecido milho moído, em comparação ao milho quebrado, em dietas para vacas em lactação alimentadas com silagem de milho e de alfafa como volumoso. Outros autores (Joy et al., 1997; Crocker et al., 1998) compararam milho floculado ao milho laminado e não observaram diferença em produção de leite, resultado semelhante ao obtido por Uchida et al. (2001) em estudo no qual compararam o milho milho moído ao milho laminado em associação à silagem de alfafa como volumoso.

Em geral, os dados comparativos do grau de moagem do milho têm apresentado efeitos variáveis na produção de leite, ao contrário do efeito positivo consistente da floculação de milho e sorgo, em comparação à moagem ou laminação (Theurer et al., 1999). Dados positivos com fontes de amido de alta degradabilidade ruminal têm sido menos freqüentes em animais mantidos em pastagens, em comparação a animais em confinamento.

O grau de moagem do milho e o tipo de subproduto não afetaram a produção de leite corrigida para 3,5\% de gordura $(\mathrm{P}>0,05)$. Nos dados revisados, as dietas com milho processado mais intensamente, apresentaram, na maioria das vezes, resultados positivos. Em alguns casos, diferenças no desempenho animal foram observadas quando as variações nos tamanhos médios de partículas do milho moído grosso e fino foram de 1,24 mm. Em outras situações, variações de até 3,6 mm não influenciaram o desempenho. De qualquer modo, na maioria desses trabalhos revisados, não houve vantagem de dietas com milho moído grosso ou laminado em comparação a dietas com milho moído fino (San Emeterio et al., 2000; Soriano et al., 2000; Reis et al., 2001; Santos et al., 2001; Dhiman et al., 2002; Nussio et al., 2002).

Não foram encontrados dados de literatura comparando polpa cítrica a casca de soja. A ausência de diferença na produção de leite entre polpa cítrica e casca de soja neste estudo sugere que os valores energéticos desses subprodutos são equivalentes.

Entretanto, a interação grau de moagem $\times$ fonte de subproduto afetou significativamente $(\mathrm{P}<0,05)$ a produ- ção de leite corrigida para 3,5\% de gordura. A combinação casca de soja com milho moído fino e polpa cítrica com milho moído grosso proporcionaram maiores produções de leite corrigidas para 3,5\% de gordura. Esse resultado pode ser conseqüência dos efeitos benéficos da casca de soja sobre o ambiente ruminal nos animais alimentados com a dieta contendo amido de maior degradabilidade ruminal, ou seja, com milho moído fino. A polpa cítrica compensou a menor degradabilidade ruminal do milho moído grosso por fornecer carboidratos não-estruturais de rápida e de extensa degradação.

Nussio et al. (2002) obtiveram maior produção de leite corrigida para 3,5\% de gordura ao fornecerem dietas contendo milho moído fino e polpa cítrica em comparação àquelas contendo apenas milho moído grosso. A combinação de milho floculado e polpa cítrica nesse estudo resultou em produção de leite corrigida para 3,5\% de gordura superior à obtida com a dieta contendo milho moído grosso.

Bernard \& Mcneill (1991), Coomer et al. (1993) e Assis et al. (2004) não observaram diferença na produção de leite quando substituíram milho por casca de soja. No trabalho de Ipharraguerre et al. (2002), a produção de leite diminuiu quando a casca de soja representou $40 \%$ da MS da dieta de vacas leiteiras.

A eficiência alimentar (LCG 3,5 / IMS) também não foi afetada pelo grau de moagem ou pelo subproduto, no entanto, como conseqüência da interação observada para produção de leite corrigida para 3,5\% de gordura, houve interação significativa desses fatores $(\mathrm{P}<0,02)$. A eficiência alimentar foi maior para as dietas com milho moído fino + casca de soja e com milho moído grosso + polpa cítrica; houve efeito da interação grau de moagem $\times$ tipo de subproduto $(\mathrm{P}<0,05)$, como conseqüência dos maiores teores de gordura do leite e da produção de leite corrigida para gordura nos animais alimentados com essas dietas.

Yu et al. (1998) constataram que a moagem fina do milho aumentou a eficiência alimentar em comparação à moagem grosseira, diferentemente dos resultados descritos por Dhiman et al. (2002), que não observaram efeito do processamento do milho sobre a eficiência alimentar.

Coomer et al. (1993) compararam vários teores de carboidratos não-estruturais na dietas ao substituírem glúten de milho e casca de soja por milho e trigo na dieta. A eficiência alimentar tendeu a aumentar conforme diminuiu a porcentagem de casca de soja na dieta.

Cunningham et al. (1993) substituíram parte do concentrado ou do volumoso por casca de soja em dietas para vacas leiteiras e não observaram diferença na eficiência alimentar. 
O teor de gordura do leite não foi influenciado pelas dietas $(\mathrm{P}>0,05)$, no entanto, a produção de gordura foi afetada pela interação grau de moagem $\times$ subproduto $(P<0,05)$, embora esses efeitos isolados não tenham alterado esse parâmetro de qualidade do leite. A produção de gordura do leite foi maior nas dietas com milho moído fino + casca de soja e com milho moído grosso + polpa cítrica $(\mathrm{P}<0,05)$, provavelmente em virtude dos efeitos benéficos das combinações dos ingredientes, como ocorreu para produção de leite corrigida para 3,5\% de gordura, da associação de diferentes subprodutos de acordo com o grau de moagem, ou degradabilidade, do milho.

Outros pesquisadores (San Emeterio et al., 2000; Soriano et al., 2000; Callison et al., 2001; Reis et al., 2001) também não observaram efeitos de diferentes formas de processamento de milho sobre o teor de gordura do leite.

Normalmente, o fornecimento de grãos de cereais processados mais intensamente (floculação $\times$ moagem fina $\times$ moagem grossa ou laminação) tende a reduzir o teor de gordura e aumentar o teor de proteína do leite (Theurer et al., 1999). Em trabalho realizado por Dhiman et al. (2002), a alimentação com milho floculado diminuiu em $7 \%$ o teor de gordura do leite em comparação ao milho moído fino.

O teor de gordura do leite no trabalho de Yu et al. (1998) foi menor nas vacas alimentadas com dietas contendo milho floculado de baixa densidade em comparação àquelas alimentadas com a dieta com milho laminado, o que pode estar associado à maior taxa de hidrólise do amido e ao efeito negativo sobre o pH ruminal. A concentração ruminal de propionato aumentou e a proporção molar de acetato:propionato diminuiu quando a disponibilidade de amido aumentou. Maior concentração de propionato ruminal aumenta a gliconeogênese, que pode estimular a secreção de insulina, inibir a liberação de ácidos graxos pelo tecido adiposo para a glândula mamária e diminuir o teor de gordura do leite. A redução no pH ruminal pode interferir na biohidrogenação ruminal e aumentar o fluxo de ácidos graxos de cadeia trans para o intestino. Esses ácidos têm efeito negativo sobre a síntese de gordura na glândula mamária (Gaynor et al., 1994).

A substituição parcial de fontes de amido por subprodutos ricos em FDN de alta digestibilidade, como a casca de soja, ou em pectina, como a polpa cítrica, pode ter efeito positivo sobre o teor de gordura do leite (Ipharraguerre et al., 2002; Santos et al., 2004). Entretanto, Bernard \& Mcneill (1991), Coomer et al. (1993) e Assis et al. (2004) também não observaram mudanças no teor e na produção de gordura do leite quando substituíram milho moído por casca de soja. Não foram encontrados trabalhos comparando casca de soja com polpa cítrica na literatura.
Não houve efeito das dietas sobre o teor de proteína do leite $(\mathrm{P}>0,05)$, semelhantemente ao observado por San Emeterio et al. (2000), Soriano et al. (2000), Reis et al. (2001) e Callison et al. (2001). Com os efeitos benéficos da associação de milho de maior degradabilidade com casca de soja e de milho de menor degradabilidade com a polpa cítrica, conforme discutido anteriormente, houve tendência $(\mathrm{P}<0,06)$ de interação grau de moagem $\times$ subproduto para produção de proteína do leite.

Entretanto, esperava-se efeito significativo do grau de moagem no teor de proteína do leite, o qual não foi observado. Os efeitos positivos do aumento da degradabilidade ruminal do amido, em resposta à floculação, sobre o teor e a produção de proteína do leite, relatados de forma consistente por Theurer et al. (1999), concordam com os dados de Wilkerson et al. (1997), que observaram maior proteína do leite quando utilizado milho moído do que milho laminado.

Knowlton et al. (1996) registraram aumento no teor de proteína do leite e Ekinci \& Broderick (1997) notaram que a produção de proteína do leite aumentou com a moagem fina do milho. Dhiman et al. (2002), por sua vez, verificaram que tanto o teor quanto a produção de proteína do leite foram maiores quando fornecidas dietas com milho moído fino em comparação a dietas com milho moído grosso. Os efeitos positivos do aumento na degradabilidade do amido sobre o teor de proteína do leite estão relacionados, provavelmente, à síntese microbiana mais intensa, que acarreta aumento no fluxo de proteína metabolizável para o intestino e melhora o perfil de aminoácidos essenciais (Santos et al., 1998).

Não houve efeito das dietas no teor de lactose do leite (P>0,05). Dhiman et al. (2002) compararam diversos métodos de processamento de milho e também não observaram efeitos no teor de lactose do leite.

Verificou-se influência $(\mathrm{P}<0,06)$ da interação grau de moagem $\times$ fonte de subproduto sobre o teor de sólidos totais, que aumentou significativamente $(\mathrm{P}<0,05)$. Por outro lado, não foram observados efeitos significativos $(\mathrm{P}>0,05)$ do grau de moagem ou do tipo de subproduto no teor de sólidos totais no leite, semelhante aos efeitos observados para os outros componentes do leite.

Não houve efeito significativo das dietas no teor de nitrogênio uréico no leite $(\mathrm{P}>0,05)$. Os efeitos benéficos da associação de milho com diferente degradabilidade ruminal e subproduto com maior teor de fibra (casca de soja) ou maior teor de carboidratos solúveis (polpa cítrica) deve ter resultado em fermentação com adequada utilização de nitrogênio amoniacal no rúmen, o que está diretamente relacionado ao nitrogênio uréico no plasma e no leite.

As dietas contendo milho moído fino resultaram em maior teor de nitrogênio uréico no leite $(\mathrm{P}<0,05)$, o que 
contraria dados observados por San Emeterio et al. (2000). Caso tenha ocorrido fermentação ruminal excessiva do amido do milho moído fino, esta fermentação poderia influenciar as taxas de degradação de carboidrato e proteína aumentando conseqüentemente o teor de nitrogênio amoniacal no fluido ruminal. Isso explicaria o maior teor de nitrogênio uréico no leite obtido com as dietas com milho moído fino, porém, não houve efeito do grau de moagem do milho sobre o teor de nitrogênio uréico no plasma, que, normalmente, é correlacionado positivamente ao teor de nitrogênio uréico no leite.

Soriano et al. (2000), Reis et al. (2001) e Dhiman et al. (2002) não observaram mudanças no teor de nitrogênio uréico no leite quando compararam milho moído fino ao milho moído grosso, assim como Uchida et al. (2001), que compararam milho moído e laminado em dietas à base de silagem de alfafa.

Os teores de nitrogênio uréico e glicose no plasma sangüíneo não foram afetados pelo grau de moagem do milho ou pelo tipo de subproduto $(\mathrm{P}>0,05)$ nem pela interação desses fatores (tratamentos). Crocker et al. (1998) também não observaram diferença no teor de glicose plasmática quando forneceram milho moído e milho floculado em diversas proporções na dieta. No entanto, o teor de nitrogênio uréico plasmático foi maior nos animais alimentados com a dieta contendo apenas milho moído, sem milho floculado.

No trabalho de Nussio et al. (2002), o teor de nitrogênio uréico plasmático foi menor nos animais alimentados com milho moído grosso em comparação ao milho floculado fornecido com polpa cítrica. O teor de glicose, no entanto, não foi afetado pelas dietas, o que está de acordo com os resultados descritos por Dhiman et al. (2002), em estudo no qual avaliaram o efeito de processamento do milho.

Os teores de glicose plasmática estão dentro das variações consideradas normais, de 35 a $55 \mathrm{mg} / \mathrm{dL}$ (Blood \& Radostits, 1989) e de 42,1 a 74,5 mg/dL (Fraser, 1989).

\section{Conclusões}

O grau de moagem do grão de milho (moído fino ou moído grosso), em associação à polpa cítrica peletizada ou casca de soja, não afetou o desempenho de vacas leiteiras com produção média de 24 kg/dia no terço médio da lactação. A polpa cítrica apresentou-se como melhor alternativa de subproduto em dietas com milho moído grosso, enquanto, em dietas com milho moído fino, a casca de soja promoveu melhores resultados.

\section{Literatura Citada}

ASSIS, A.J.; CAMPOS, J.M.S.; OLIVEIRA, A.S. et al. Casca de soja em dietas de vacas leiteiras. I - Consumo, variação de peso, produção e composição do leite. In: REUNIÃO ANUAL DA SOCIEDADE BRASILEIRA DE ZOOTECNIA, 41., 2004, Campo Grande. Anais... Campo Grande: Sociedade Brasileira de Zootecnia, 2004. (CD-ROM).

BERNARD, J.K.; McNEILL, W.W. Effect of high fiber energy supplements on nutrient digestibility and milk production of lactating dairy cows. Journal of Dairy Science, v.74, n.3, p.991-995, 1991.

BLOOD, D.C.; RADOSTITIS, O.M. Clínica veterinária. 7.ed. Rio de Janeiro: Guanabara, 1989. 1263p.

CALLISON, S.L.; FIRKINS, J.L.; EASTRIDGE, M.L. et al. Site of nutrient digestion by dairy cows fed corn of different particle sizes or steam-rolled. Journal of Dairy Science, v.84, n.6, p.1458-1467, 2001.

COOMER, J.C.; AMOS, H.E.; WILLIAMS, C.C. et al. Response of early lactation cows to fat supplementation in diets with different nonstructural carbohydrate concentrations. Journal of Dairy Science, v.76, n.12, p.3747-3754, 1993.

CROCKER, L.M.; DEPETERS, E.J.; FADEL, J.G. et al. Influence of processed corn grain in diets of dairy cows on digestion of nutrients and milk composition. Journal of Dairy Science, v.81, n.9, p.2394-2407, 1998.

CUNNINGHAM, K.D.; CECAVA, M.J.; JOHNSON, T.R. Nutrient digestion, nitrogen, and amino acid flows in lactating cows fed soybean hulls in place of forage or concentrate. Journal of Dairy Science, v.76, n.11, p.3523-3535, 1993.

DHIMAN, T.R.; ZAMAN, M.S.; McQUEEN, I.S. et al. Influence of corn processing and frequency of feeding on cow performance. Journal of Dairy Science, v.85, p.217-226, 2002.

EKINCI, C.; BRODERICK, G.A. Effect of processing high moisture ear corn on ruminal fermentation and milk yield. Journal of Dairy Science, v.80, n.12, p.3298-3307, 1997.

FRASER, C.M. Manual Merck de veterinária. 6.ed. São Paulo: Roca, 1991. 2169p.

GAYNOR, P.J.; ERDMAN, R.A.; TETER, B.B. et al. Milk fat yield and composition during abomasal infusion of cis or trans octadecenoates in holstein cows. Journal of Dairy Science, v.77, p.157-165, 1994.

IPHARRAGUERRE, I.R.; CLARK, J.H. Soyhulls as an alternative feed for lactating dairy cows: a review. Journal of Dairy Science, v.86, p.1052-1073, 2003.

IPHARRAGUERRE, I.R.; IPHARRAGUERRE, M.M.; CLARK, J.H. Performance of lactating dairy cows fed varying amounts of soyhulls as a replacement for corn grain. Journal of Dairy Science, v.85, p.2905-2912, 2002.

JOY, M.T.; DEPETERS, E.J.; FADEL, J.G. et al. Effects of corn processing on the site and extent of digestion in lactating dairy cows. Journal of Dairy Science, v.80, n.9, p.2087-2097, 1997.

KNOWLTON, K.F.; ALLEN, M.S.; ERICKSON, P.S. Lasalocid and particle size of corn grain for dairy cows in early lactation. 1. Effect on performance, serum metabolites, and nutrient digestibility. Journal of Dairy Science, v.79, p.557-564, 1996.

KNOWLTON, K.F.; GLENN, B.P.; ERDMAN, R.A. Performance, ruminal fermentation, and site of starch digestion in early lactation cows fed corn grain harvested and processed differently. Journal of Dairy Science, v.81, p.1972-1984, 1998.

MARTINEZ, J.C.; SANTOS, F.A.P.; VOLTOLINI, T.V. et al Substituição parcial do milho moído fino por polpa cítrica peletizada no concentrado de vacas Holandesas em início de lactação, pastejando capim-elefante. 1. Produção e composição do leite, parâmetros sangüíneos, peso vivo e escore corporal. 
In: REUNIÃO ANUAL DA SOCIEDADE BRASILEIRA DE ZOOTECNIA, 40., 2003, Santa Maria. Anais... Santa Maria: Sociedade Brasileira de Zootecnia, 2003. (CD-ROM).

MOREIRA, P.C.; REIS, R.B.; LANA, A.M.Q. et al. Produção e composição do leite de vacas alimentadas com polpa cítrica em substituição ao milho grão. In: REUNIÃO ANUAL DA SOCIEDADE BRASILEIRA DE ZOOTECNIA, 41., 2004, Campo Grande. Anais... Campo Grande: Sociedade Brasileira de Zootecnia, 2004. (CD-ROM).

NATIONAL RESEARCH COUNCIL - NRC. Nutrient requirements of domestic animals. Nutrient requeriments of dairy cattle. 7.ed.rev. Washington, D.C.: National Academy of Science, 2001. 381p.

NUSSIO, C.M.B.; SANTOS, F.A.P.; PIRES. A.V. et al. Fontes de amido de diferentes degradabilidades e sua substituição por polpa de citrus em dietas para vacas leiteiras. Acta Scientiarum, v.24, n.4, p.1079-1086, 2002.

POORE, M.H.; MOORE, J.A.; SWINGLE, R.S. et al. Effect of fiber source and ruminal starch degradability on site and extent of digestion in dairy cows. Journal of Dairy Science, v.76, p.2244, 1993.

REIS, R.B.; SAN EMETERIO, F.; COMBS, D.K. et al. Effects of corn particle size and source on performance of lactating cows fed direct-cut grass-legume forage. Journal of Dairy Science, v.84, p.429-441, 2001.

SAN EMETERIO, F.; REIS, R.B.; CAMPOS, W.E. et al. Effect of coarse or fine grinding on utilization of dry or ensiled corn by lactating dairy cows. Journal of Dairy Science, v.83, p.29392848, 2000.

SANTOS, F.A.P.; HUBER, J.T.; THEURER. C.B. Milk yield and composition of lactating cows fed steam-flaked sorghum and graded concentrations of ruminally degradable protein. Journal of Dairy Science, v.81, p.215-220, 1998.

SANTOS, F.A.P.; MENEZES JR., M.P.; SIMAS, J.M.C. et al. Processamento do grão de milho e sua substituição parcial por polpa de citros peletizada sobre o desempenho, digestibilidade de nutrientes e parâmetros sangüíneos. Acta Scientiarum, v.23, n.4, p.923-931, 2001.

SANTOS, F.A.P.; MARTINEZ, J.C.; CARMO, C.A. et al. Sistema de alimentação com mecanismos de flexibilidade para a produção de leite. In: ZOCCAL, R.; AROEIRA, L.J.M.; MARTINS, P.C. et al. (Eds.) Leite: uma cadeia produtiva em transformação. Juiz de Fora: Embrapa Gado de Leite, 2004. p.117-161.

STATISTICAL ANALYSIS SYSTEM - SAS. User's guide; statistics. Version 8. Cary: 1999. 965p.
SCOTON, R.A.; SANTOS, F.A.P.; IMAIZUMI, H. et al. Substituição do milho moído fino por polpa cítrica peletizada e/ou raspa de mandioca na dieta de vacas leiteiras em final de lactação. In: REUNIÃO ANUAL DA SOCIEDADE BRASILEIRA DE ZOOTECNIA, 40., 2003, Santa Maria. Anais... Santa Maria: Sociedade Brasileira de Zootecnia, 2003. (CD-ROM).

SORIANO, F.D.; POLAN, C.E.; MILLER, C.N. Milk production and composition, rumen fermentation parameters, and grazing behavior of dairy cows supplemented with different forms and amounts of corn grain. Journal of Dairy Science, v.83, p.1520-1529, 2000.

THEURER, C.B.; HUBER, J.T.; DELGADO, E. et al. Invited review: summary of steam-flaking corn or sorghum grain for lactating dairy cows. Journal of Dairy Science, v.82, p.1950-1959, 1999.

UCHIDA, K.; BALLARD, C.S.; MANDEBVU, P. et al. Effect of variation in proportion of corn meal and steam-rolled corn in diets for dairy cows on behavior, digestion and yield and composition of milk. Journal of Dairy Science, v.84, n.2, p.453-461, 2001.

Van SOEST, P.J.; ROBERTSON, J.B.; LEWIS, B.A. Methods for dietary fiber, neutral detergent fiber, and nonstarch polysaccharides in relation to animal nutrition. Journal of Dairy Science, v.74, p.3583, 1991.

WAINMAN, F.W.; DEWEY, J.S. Feedstuffs evaluation unitfifth report. Chalcombe: Rowett Research Institute, 1988. $123 p$.

WILDMAN, E.E.; JONES, G.M.; WAGNER, P.E. et al. A dairy condition scoring system and its relationship to selected production characteristics. Journal of Dairy Science, v.65, p.495, 1982.

WILKERSON, V.A.; GLENN, B.P.; MCLEOD, K.R. Energy and nitrogen balance in lactating dairy cows fed diets containing dry or high moisture corn in either rolled or ground form. Journal of Dairy Science, v.80, n.10, p.2487-2097, 1997.

YU, P.; HUBER, J.T.; SANTOS, F.A.P. Effects of ground, steamflaked, and steam-rolled corn grains on performance of lactating dairy cows. Journal of Dairy Science, v.81, n.3, p.777-783, 1998. 